Tropical Journal of Pharmaceutical Research July 2017; 16 (7): 1711-1716

ISSN: $1596-5996$ (print); 1596-9827 (electronic)

(C) Pharmacotherapy Group, Faculty of Pharmacy, University of Benin, Benin City, 300001 Nigeria.

All rights reserved.

Available online at http://www.tjpr.org

Original Research Article

http://dx.doi.org/10.4314/tjpr.v16i7.32

\title{
Assessment of changes in lipid profile and related enzymes in children with asthma
}

\author{
Li-Ping Zhu ${ }^{1}$, Cheng-Jun Yan ${ }^{2}$, Qing-Jian $\mathrm{Wu}^{2}$, Cun-Xue Zhang ${ }^{1}$, Xiu-Tai Yuan ${ }^{1}$ \\ and Ti-Kun Fang ${ }^{2 \star}$ \\ ${ }^{1}$ Department of Pediatrics, ${ }^{2}$ Department of Emergency, Jining No. 1 People's Hospital, Jining, Shandong 272011, China
}

*For correspondence: Email: fangtikun@hotmail.com; Tel/Fax: 0086-537-2253684

Sent for review: 9 December 2016

Revised accepted: 7 June 2017

\begin{abstract}
Purpose: To investigate the influence of the lipid profile and related parameters on the development of asthma in children aged 10 to 15 years.

Methods: Peripheral blood samples were collected from a group diagnosed with asthma as well as from a healthy control group. The lipid profile parameters measured were total cholesterol (TC), triglycerides (TG), low-density lipoprotein (LDL), very-low-density lipoprotein (VLDL), high-density lipoprotein (HDL), serum total antioxidant capacity (TAC), reduced glutathione (GSH), and malondialdehyde (MDA), and the activities of lecithin-cholesterol acyltransferase (LCAT) and cholesteryl ester transfer protein (CETP).

Results: TC, TG, LDL, and VLDL levels were significantly $(p \leq 0.05)$ higher in the asthma group compared with the controls, while HDL level was lower. Total TAC and GSH were lower in the asthma group, while MDA level, and LCAT and CETP activities were higher.

Conclusion: There is a link between an elevated lipid profile and increased antioxidant capacity in asthmatic children.
\end{abstract}

Tropical Journal of Pharmaceutical Research is indexed by Science Citation Index (SciSearch), Scopus, International Pharmaceutical Abstract, Chemical Abstracts, Embase, Index Copernicus, EBSCO, African Index Medicus, JournalSeek, Journal Citation Reports/Science Edition, Directory of Open Access Journals (DOAJ), African Journal Online, Bioline International, Open-J-Gate and Pharmacy Abstracts

\section{INTRODUCTION}

Asthma is a heterogeneous disease that affects both children and adults, and is characterized by chronic inflammation in the respiratory tract due to continuous inflammatory stress signaling or chronic exposure to allergens [1]. Symptoms of asthma include wheezing, shortness of breath, tightness in the chest, and cough of varying intensity [1]. Asthma is a chronic health problem that affects $20 \%$ of children worldwide [2]. Globally, asthma-related problems have increased by $30 \%$ over the past 20 years [3].
Measurement of the nitric oxide concentration in exhaled breath is a noninvasive method of monitoring the status of airway inflammation due to asthma in children older than 1 year [4]. Any infection in the upper respiratory tract with recurrent coughing and wheezing, followed by an elevated concentration of exhaled nitric oxide for more than 4 weeks, is taken as a clinical marker of asthma in children $[5,6]$.

Reports suggest a strong correlation between oxidative stress and lung 
diseases, including asthma, chronic obstructive pulmonary disorder, cystic fibrosis, and lung cancer [7]. In the body, oxidative stress is mitigated by the antioxidant system, which consists of enzymatic and non-enzymatic antioxidants [8]. Failure of the antioxidant defense system can result in oxidant-mediated injury, leading to cell death [8]. Acute asthma exacerbations may lead to increased oxidative stress, which in turn causes reduced superoxide dismutase (SOD) activity [9]. It has been reported that extracellular glutathione (GSH) peroxidase activity is increased in the bronchial epithelial cells of asthmatic subjects [10,11]. Superoxide and hydrogen peroxide radicals also increase vascular endothelial growth factor expression, which can be blocked by antioxidants [12].

Advances in the diagnosis of asthma have led to both under- and overdiagnosis of the disease [2]. Underdiagnosis could lead to an increased burden and higher healthcare costs, while over-diagnosis could lead to higher treatment costs and exposure to unwanted side-effects. Globally, nearly one-third of all children and adolescents are classified as either overweight or obese and show abnormal lipid profiles [13]. Therefore, it is very important to identify correlations among the clinical parameters and markers that can help to diagnose asthma accurately. This study examined the correlations between asthma in children and the lipid profile and related blood parameters, with the aim being to identify factors that favor the initiation and development of asthma.

\section{METHODS}

\section{Study design and subjects}

Children between 10 and 15 years of age, and presenting to Jining No. 1 People's Hospital, Shandong, China for asthma treatment, were initially screened for symptoms of asthma using a standard protocol. Children diagnosed with asthma were selected randomly for inclusion in the study. The study objectives, experimental design, and protocol were explained to the subjects in the presence of their parents or legal guardians, from whom written consent was obtained. Age, sex, height $(\mathrm{m})$, and weight $(\mathrm{kg})$ data were collected. The body mass index (BMI) of the subjects was calculated using the standard formula $\left(\mathrm{kg} / \mathrm{m}^{2}\right)$. The study matched 59 children (28 boys, 31 girls) in the asthma group by age and gender with 57 (29 boys, 28 girls) children in the control group. After a minimum 10-h fast, $7 \mathrm{~mL}$ of venous blood was collected from each subject. Serum was prepared from the blood samples in a refrigerated table-top centrifuge and stored at $-80{ }^{\circ} \mathrm{C}$ until analysis. The experiment was approved by the Ethical Review Committee of the Jining No.1 People's Hospital (approval Ref no 1603312) complied with international guidelines [14].

\section{Determination of lipid profile parameters}

The total cholesterol (TC), high-density lipoprotein (HDL) cholesterol and triglycerides (TG) were assayed using commercial kits (BioSino Bio-technology and Science, Shanghai, China), following the manufacturer's instructions. Low-density lipoprotein (LDL) cholesterol was calculated from the measured TC, $\mathrm{TG}$, and HDL cholesterol using the following formula: LDL-cholesterol = total-cholesterol - HDL-cholesterol [TG/5], where [TG/5] is an estimate of very-low-density lipoprotein (VLDL) cholesterol; all values are in mg/dL [15].

\section{CETP and LCAT assays}

The CETP and lecithin-cholesterol acyltransferase (LCAT) activities were assayed in serum using commercial fluorometric assay kits (Roar Biomedical, 
New York, NY, USA). Buffers and reagents were used as provided, and the standard assay protocol followed the manufacturer's instructions. CETP Activity Assay Kit uses a proprietary substrate that enables the detection of CETP-mediated transfer of neutral lipid from the substrate to a physiological acceptor. The transfer activity results in an increase in fluorescence intensity. LCAT activity was obtained by a fluorometric assay that measures the phospholipase activity of LCAT.

\section{Determination of the total antioxidant capacity of serum}

The total antioxidant capacity (TAC) of the serum was measured based on a colorimetric method developed by Erel [16]. The assay mixture consists of ferrous ion solution and hydrogen peroxide, which produce hydroxyl radicals that generate brown dianisidinyl radical cations. The antioxidant capacity of the serum was measured against the potent free radical reactions initiated by the hydroxyl radicals produced. The assay results are expressed in $\mathrm{mM}$ of Trolox equivalents/L.

\section{Evaluation of serum reduced glutathione}

Reduced GSH in serum was analyzed using the method of Ellman et al [17] and expressed in $\mathrm{mg} / \mathrm{dL}$. This enzymatic recycling method uses GSH reductase to quantify GSH. The sulfhydryl group of GSH reacts with 5,5'-dithio-bis-2nitrobenzoic acid (Ellman's reagent) and produces yellow 5-thio-2-nitrobenzoic acid (TNB). Oxidized glutathione (GSSG) is then reduced to GSH by GSH reductase, using reducing equivalents provided by NADPH. The rate of TNB formation is proportional to the sum of GSH and GSSG present in the sample, determined by measuring the formation of TNB at $412 \mathrm{~nm}$.

\section{Serum malondialdehyde levels}

Malondialdehyde (MDA) in serum was analyzed using the method of Ohkawa et al [18]. Briefly, serum was reacted with trichloroacetic acid containing 2thiobarbituric acid, and the mixture was incubated at $95{ }^{\circ} \mathrm{C}$ for $20 \mathrm{~min}$ and then cooled in ice. The thiobarbituric acid content was measured as the MDA $(\varepsilon=$ $155 \mathrm{mM}^{-1} \mathrm{~cm}^{-1}$ ) content at $A_{532}$ using a spectrophotometer and expressed as $\mathrm{nM} / \mathrm{L}$.

\section{Statistical analysis}

All group data are presented as mean \pm SD. Significant differences between the groups were analyzed using one-way analysis of variance followed by Tukey's honestly significant difference post-hoc test. Statistical significance was set at $p$ $\leq 0.05$.

\section{RESULTS}

Table 1 summarizes the subjects' characteristics. The mean age did not differ significantly between the two groups, so there was no age-related bias. BMI was markedly higher in the asthma group.

Table 1: Characteristics of subjects in the asthma and control groups

\begin{tabular}{lcc}
\hline Parameter & Asthma & Control \\
\hline Age (years) & $12.5 \pm 2.3$ & $12.8 \pm 2.5$ \\
Sex (M:F) & $28: 31$ & $29: 28$ \\
Weight $(\mathrm{kg})$ & $32.3 \pm 4.7$ & $28.6 \pm 3.8$ \\
BMl $\left(\mathrm{kg} / \mathrm{m}^{2}\right)$ & $25.6 \pm 3.2$ & $20.4 \pm 2.7$ \\
\hline
\end{tabular}

$B M I=$ body mass index

TC, TG, LDL, and VLDL levels were significantly increased in the asthma group $(30.12,24.17$, 28.66, and $17.15 \%$ higher than those of the controls, respectively; Table 2). As expected, there was a corresponding decrease in HDL level in the asthma group, which was $15.08 \%$ lower than that of the controls. CETP activity was 13.54 $\%$ higher in the asthma versus control group, and the difference was significant. LCAT activity was $9.4 \%$ higher in the asthma than in the control group, but the difference was not significant. 
TAC was decreased by $33.33 \%$ in the asthma group relative to the controls, while the serum MDA was increased by $47.59 \%$, and the serum GSH was decreased by $12.09 \%$.

Malondialdehyde (MDA) level was significantly higher $(p \leq 0.05)$ in asthma group. On the other hand, glutathione (GSH) levels was significantly lower in the asthma compared to the control groups.

Table 2: Lipid profiles of the asthma and control groups. Values are means \pm SD (units: $\mathrm{mg} / \mathrm{dL}$ )

\begin{tabular}{lcc}
\hline Parameter & Asthma & Controls \\
\hline TC & $189.63 \pm 16.56^{*}$ & $145.74 \pm 16.71$ \\
HDL & $42.39 \pm 5.42^{*}$ & $49.92 \pm 3.94$ \\
TG & $133.49 \pm 15.98^{*}$ & $107.51 \pm 11.38$ \\
VLDL & $26.23 \pm 2.65^{*}$ & $22.39 \pm 2.14$ \\
LDL & $108.55 \pm 9.38^{*}$ & $84.37 \pm 10.27$ \\
\hline TC, total & cholesterol; HDL, high-density \\
lipoprotein; TG, triglycerides; VLDL, very-low- \\
density lipoprotein; $L D L$, low-density lipoprotein; \\
* $p \leq 0.05$
\end{tabular}

\section{DISCUSSION}

Higher mitochondrial cholesterol levels can lead to impaired GSH transport across the mitochondrial membrane, inhibiting the removal of free radicals generated in mitochondria and the excessive accumulation of reactive oxygen species (ROS) [11]. This could result in mitochondrial DNA damage, loss of essential mitochondrial protein synthesis, and progressive respiratory dysfunction, in turn leading to many diseases [8]. In our study, the significantly elevated cholesterol and LDL and VLDL levels are clues to the role of the lipid profile and increased free radical generation in asthma.

Ectopic expression of the $\alpha$ - and $\beta$-chains of ATP synthase in liver cells is essential for HDL catabolism [19]; disturbance in this expression could lead to disease. The low serum HDL cholesterol levels observed in the children in our study could be the reason for the initiation or development of asthma.

Invasive and non-invasive interventions have been developed to increase HDL cholesterol, and decrease LDL cholesterol, in blood and to promote health.

Cholesteryl ester transfer protein (CETP) and lecithin cholesterol acyl transferase (LCAT) are enzymes involved in HDL remodeling and metabolism [20]. CETP facilitates the exchange of TG with cholesteryl ester, or vice versa, between HDL and other lipoproteins, ultimately leading to lower $\mathrm{HDL}$, and higher $\mathrm{LDL}$ and VLDL, levels [21]. The increased CETP activity in the asthma group in our study explains the occurrence of metabolic reactions that favor the production of lipoproteins other than HDL, which might in turn explain the elevated LDL and VLDL levels, and decreased HDL level, among the asthmatic children.

$T G$ is a vital molecule for determining the HDL level in blood. An increased blood TG level could cause the addition of TG molecules to HDL, leading to hydrolysis by hepatic lipase and a reduction in the blood HDL level [22]. LCAT esterifies cholesterol via an acyl group, derived preferably from HDL molecules [23]. Abnormal lipid molecules have been observed in the absence of LCAT activity [23]. In our study, the LCAT activity was increased slightly, albeit not significantly, in the asthma group.

Free radicals, which generate ROS, are produced via electron transport in mitochondria, and by NADPH oxidase activity in neutrophils, monocytes and macrophages,

molybdenum hydroxylase, and arachidonic acid metabolism, which reacts with metal prosthetic groups or iron-sulfur centers in proteins, causing loss of functionality $[11,24]$.

Various cell types initiate the antioxidant defense process via enzymatic and nonenzymatic antioxidants [11]. In a biological system, the ratio between the 
inter-convertible oxidized and reduced forms of a specific protein or molecular pair is used to evaluate the redox environment and its reducing capacity [24]. In the present study, the significantly lower TAC and GSH levels seen in asthmatic patients versus controls support previous reports of increased MDA levels. GSH may be present in high concentrations in blood and the lungs.

Lung epithelium contains 300 micromoles of GSH, more than $90 \%$ of which is in reduced form [25]. The importation of reduced GSH into cells, and exportation of oxidized GSH, could contribute to a reduction in oxidative stress [12]. In the present study, the lower GSH levels in the blood of the asthma subjects might have been insufficient for transport into the lungs, which could lead to the initiation and development of asthma. The data support the hypothesis that ROS and reactive nitrogen species (RNS) are responsible for the inflammation (via the the accumulation of inflammatory cells), airway obstruction, and hyperresponsiveness seen in asthma [26], while ROS-mediated modifications in oxidation have been linked with asthma severity [27].

As our subjects were young, and thus had a high basal metabolic rate and level of physical activity, their tidal volume might also be high. An abundance of oxygen in the lungs could be responsible for adding more ROS and RNS to the reactive radicals produced metabolically [11]. This could worsen asthma still further, if not balanced by the removal of radicals via interventions based on nutritional supplements and detoxifiers.

\section{Study limitations}

Lipid-related complications might preinitiate disease, which could lead to asthma and many other related disorders. Although a clear connection between antioxidative capacity and asthma in obese children has been established, more work is needed to establish these parameters as biomarkers.

\section{CONCLUSION}

We established clear connections among asthma, the lipid profile, and antioxidant defense in obese children. The TC, TG, LDL, and VLDL levels, and LCAT and CETP activities, were significantly higher in our asthma versus control group. The asthmatic patients also suffered from oxidative stress and subsequent inflammation.

\section{DECLARATIONS}

\section{Acknowledgement}

None declared.

\section{Conflict of Interest}

No conflict of interest associated with this work.

\section{Contribution of Authors}

The authors declare that this work was done by the authors named in this article and all liabilities pertaining to claims relating to the content of this article will be borne by them.

\section{Open Access}

This is an Open Access article that uses a funding model which does not charge readers or their institutions for access and distributed under the terms of the Creative Commons Attribution License (http://creativecommons.org/licenses/by/ 4.0) and the Budapest Open Access Initiative (http://www.budapestopenaccessinitiative.org/rea d), which permit unrestricted use, distribution, and reproduction in any medium, provided the original work is properly credited.

\section{REFERENCES}

1. Brand PL, Baraldi E, Bisgaard H, Boner AL, CastroRodriguez JA, Custovic A, de Blic J, de Jongste JC, Eber E, Everard ML et al. Definition, assessment and treatment of wheezing disorders in preschool children: an evidence-based approach. Eur Respir J 2008; 32: 1096-1110 
2. Lai CK, Beasley R, Crane J, Foliaki S, Shah J, Weiland $S$. Global variation in the prevalence and severity of asthma symptoms: phase three of the International Study of Asthma and Allergies in Childhood (ISAAC). Thorax 2009; 64: 476-483.

3. Vos $T$, Flaxman $A D$, Naghavi M, Lozano R, Michaud C, Ezzati M, Shibuya K, Salomon JA, Abdalla S, Aboyans $V$ et al. Years lived with disability (YLDs) for 1160 sequelae of 289 diseases andinjuries 1990-2010: a systematic analysis for the Global Burden of Disease Study 2010. Lancet 2012; 380: 2163-2196.

4. Van Der Heijden HH, Brouwer ML, Hoekstra F, van der Pol P, Merkus PJ. Reference values of exhaled nitric oxide in healthy children 1-5 years using off-line tidal breathing. Pediatr Pulmonol 2014; 49: 291-295.

5. Singer $F$, Luchsinger I, Inci $D$, Knauer $N$, Latzin $P$, Wildhaber JH, Moeller A. Exhaled nitric oxide in symptomatic children at preschool age predicts later asthma. Allergy 2013; 68: 531-538.

6. Silkoff PE, Caramori $M$, Tremblay $L$, McClean $P$, Chaparro C, Kesten S, Hutcheon M, Slutsky AS, Zamel $N$, Keshavjee $S$. Exhaled nitric oxide in human lung transplantation. A non-invasive marker of acute rejection. Am J RespirCrit Care Med 1998; 157: 18221828.

7. Halliwell B, Gutteridge J, Cross CE. Free radicals antioxidants and human disease: where are we now? J Clin Lab Med 1992; 119: 598-620.

8. Heffner JE, Repine JE. Pulmonary strategies of antioxidant defense. Am Rev Respir Dis 1989; 140: 531 . 554.

9. MacPherson JC, Comhair SA, Erzurum SC, Klein DF, Lipscomb MF, Kavuru MS, Samoszuk MK, and Hazen SL. Eosinophils are a major source of nitric oxidederived oxidants in severe asthma: Characterization of pathways available to eosinophils for generating reactive nitrogen species. J Immunol 2001; 166: 57635772.

10. Comhair SA, Erzurum SC. Antioxidant responses to oxidant-mediated lung diseases. Am J Physiol Lung Cell Mol Physiol 2002; 283: L246-255.

11. Comhair SA, Bhathena PR, Farver $C$, Thunnissen $F B$, Erzurum SC. Extracellular glutathione peroxidase induction in asthmatic lungs: Evidence for redox regulation of expression in human airway epithelial cells. FASEB J 2001; 15: 70-78.

12. Kuroki M, Voest EE, Amano S, Beerepoot LV, Takashima S, Tolentino M, Kim RY, Rohan RM, Colby KA, Yeo KT, Adamis AP. Reactive oxygen intermediates increase vascular endothelial growth factor expression in vitro and in vivo. J Clin Invest 1996; 98: 1667-1675.

13. Yan EG, Munir KM. regulatory and ethical principles in research involving children and individuals with developmental disabilities. Ethics \& Behavior. 2004; 14 (1): 31-49.

14. Warnick GR, Knopp RH, Fitzpatrick $V$ and Branson L: Estimating low-density lipoprotein cholesterol by the Friedewald equation is adequate for classifying patients on the basis of nationally recommended cutpoints. Clin Chem 1990; 36 (1): 15-19.

15. Erel O. A novel automated method to measure total antioxidant response against potent free radical reactions. Clin Biochem 2004; 37:112-119.

16. Ellman GL. Tissue sulfhydryl groups. Arch Biochem Biophy 1959; 82 (1): 70-77.

17. Ohkawa H, Ohishi N, Yagi K. Assay for lipid peroxides in animal tissues by thiobarbituric acid reaction. Anal Biochem 1979; 95: 351-358.

18. Martinez LO, Jacquet S, Esteve JP, Rolland C, Cabezon E, Champagne E, Pineau T, Georgeaud V, Walker JE, Terce $F$ et al. Ectopic beta-chain of ATP synthase is an apolipoprotein A-I receptor in hepatic HDL endocytosis. Nature 2003; 421 (6918): 75-79.

19. Park KH, Shin DG, Kim JR, Hong JH, Cho KH. The functional and compositional properties of lipoproteins are altered in patients with metabolic syndrome with increased cholesteryl ester transfer protein activity. Int $J$ Mol Med 2010; 25: 129-136.

20. Huang $Y$, Wu $Y$, Liu R, Fan $P$, Zhang J, Wang F, Luo $X$, Liu $Y$, Liu B, Bai H. Differential effect of ATP binding cassette transporter $A 1$ R219K and cholesteryl ester transfer protein TaqIB genotypes on HDL-C levels in overweight/obese and non-obese Chinese subjects. Acta Cardiol 2011; 66: 231-237.

21. Hokanson JE, Brunzell JD, Jarvik GP, Wijsman EM, Austin MA. Linkage of low-density lipoprotein size to the lipoprotein lipase gene in heterozygous lipoprotein lipase deficiency. Am J Hum Genet 1999; 64: 608-618.

22. Norum KR, Glomset JA, Nichols AV, Forte T. Plasma lipoproteins in familial lecithin-cholesterol acyltransferase deficiency: physical and chemical studies of low and high density lipoproteins. J Clin Invest 1971; 50: 1131-1140.

23. Pham-Huy LA, He H, Pham-Huy C. Free radicals, antioxidants in disease and health. Int $\mathrm{J}$ Biomed Sci. 2008; 4 (2): 89-96.

24. Roum JH, Buhl R, McElvaney NG, Borok Z, Crystal RG. Systemic deficiency of glutathione in cystic fibrosis. $J$ Appl Physiol 1993; 75: 2419-2424.

25. Hoshino T, Okamoto M, Takei S, Sakazaki Y, Iwanaga T, Aizawa $H$. Redox-regulated mechanisms in asthma. Antioxid Redox Signal 2008; 10: 769-783.

26. Sandstrom J, Nilsson P, Karlsson K, Marklund SL. 10fold increase in human plasma extracellular superoxide dismutase content caused by a mutation in heparinbinding domain. J Biol Chem 1994; 269: 19163-19166. 